\title{
Competitive tendering in the Scottish National Health Service Was it compulsory, and did it make a difference?(*)
}

\author{
by
}

\author{
Robin G. Milne \\ Department of Economics \\ University of Glasgow \\ Glasgow, Scotland \\ G12 8RT \\ and \\ Robert E. Wright \\ Department of Economics \\ University of Stirling \\ Stirling, Scotland \\ FK9 4LA
Human Resources Research Programme
Centre for Economic Policy Research
90-98 Goswell Road
London, England \\ EC1V 7DB
}

March 1999

(*) Financial support from the Nuffield Foundation is gratefully acknowledged. We are also grateful to various Health Boards and NHS Trusts, and to the Scottish Office Department of Health, for supplying some of the data presented in this paper and comments on an earlier draft. Mary Latham provided excellent research assistance. The views expressed in this paper are however our own. 


\begin{abstract}
This paper examines the implementation of competitive tendering in the Scottish National Health Service. Data relating to cleaning, catering and laundering services-the three services targeted for competitive tendering--are examined. Our analysis suggests that for the first four years the request to market test was largely ignored in Scotland. In 1987 it become a management requirement, and within three years of its fresh start implementation of this policy more than matched the corresponding experience in England.
\end{abstract}




\section{Competitive tendering in the Scottish National Health Service Was it compulsory, and did it make a difference? $(*)$}

\section{Introduction}

It was commonplace in the 1970s for support services in the public sector to be provided "in house" by direct service organisations. The arrival of successive Conservative governments, initially under the leadership of Margaret Thatcher, decided it would be appropriate to test the efficient provision of these support services. A distinctive feature of this process was that support services were put out to competitive tender. The economic motivation was that subjecting these activities to competition should result in services being delivered at lower cost thereby (in theory) release resources for other purposes. Early starts were made in local and central government. Legislative measures were used for local government, first in 1980 and then 1988, and the expression 'compulsory competitive tendering' (emphasis added) became common parlance. Implementation in central government had a much lower public profile.

This paper looks at the experience of competitive tendering in the National Health Service [NHS], and particularly what happened in Scotland. The focus, in Scotland as throughout the rest of the United Kingdom, was on cleaning, catering and laundering services. Health boards (and authorities) were also encouraged to include others services, though none were identified by name in the initial guidance. In this paper Scotland's experience is compared to that of England (and to a lesser extent to Northern Ireland and Wales). More specifically, the aim is to answer two related questions. The first is: Was competitive tendering in practice 'compulsory', even though it never had statutory force? The second is: Was competitive tendering 
successful in terms of coverage and costs saved? Our analysis suggests that for the first four years competitive tendering was not compulsory. Only in 1987 did it effectively become so, and within three years of its fresh start the policy more than matched the corresponding experience in England.

\section{From "Ask" to "Require"}

This section addresses the issue of 'compulsion'. In fact we are not aware that the word 'compulsion' has ever been used in official guidance issued to health boards and authorities by the central government Health Departments. At first boards were 'asked', like their English authority counterparts, to follow the guidance by their respective Health Departments (SHHD, 1983). The strongest statement to be found in the Scottish guidance was: "There is a special obligation on Boards ... where service costs are significantly above average ..." (Ibid para 5). As we show below, the Scottish boards responded rather differently to the initial request than did their English counterparts. Later the boards were 'required' to follow the guidance.

Information on expenditure on the three hotel services in the financial year 1984-85, by health board, is given in table 1. As this table shows, expenditure in

Scotland (as a whole) was considerably higher than in any single English Regional Health Authority [RHA] that year, varying from $£ 15 \mathrm{~m}$ to $£ 45 \mathrm{~m}$ for domestic services; $£ 13 \mathrm{~m}$ to $£ 37 \mathrm{~m}$ for catering; and $£ 3 \mathrm{~m}$ to $£ 6 \mathrm{~m}$ for laundry (Social Services Committee, 1986 , table 7.1 ). The overall total of $£ 131 \mathrm{~m}$ represented $7.7 \%$ of total current expenditure on the Scottish NHS in that year.

$$
<<<<\text { Table } 1 \text { About Here }>>>>
$$

No invitations to tender were issued by the health boards in Scotland in the first six months of 1983. The National Audit Office identified a number of difficulties 
(NAO, 1987, part 4). First, the number of private contractors capable of delivering the required services was limited. This was particularly the case of laundries, of which there were only nine in Scotland with a combined spare capacity of less than one per cent of NHS work. Significantly, the National Audit Office indicated that "boards were accordingly required to tender only where there was sufficient capacity" (emphases added). Second, there was strong opposition, particularly from the trades unions. And third, the National Audit Office referred to "pressures from structural reorganisation" within the health boards. The report did not spell out what these were. Levitt et al (1995, p 101) suggest there had been a delay in implementation of reorganisation in Scotland (SHHD, 1979). This had been planned for 1 April 1982, but "took much longer".

In response to these difficulties, further guidance was issued by the Department in June 1984, which set out a short and a long-term programme for health boards (SHHD, 1984). In the short term, by the end of March 1985, each health board was required to put out to tender the domestic and catering services for their head office and at least two hospitals. In the longer term, the boards are "asked" to draw up a programme showing when, during the three year period to the end March 1988, the remaining domestic, catering and laundry services would be reviewed and put out to tender. The three Islands health boards of Orkney, Shetland and the Western Isles were exempt, but were expected to make efficiency savings by other means.

In August 1984 Fife Health Board, followed by Greater Glasgow, Lothian, Highland, and Argyll and Clyde Health Boards, announced they would not put these services out to tender. Instead they would seek to make savings through "joint management/union efficiency reviews" (NAO, 1987, para 4.5). The five health boards accounted for some $55 \%$ of expenditure on these three services in Scotland (see table 
1 above). In July 1985 the Minister for Health and Social Work indicated that health boards not taking the route of market testing would be set cost savings targets in the financial year 1985-86 of 10\% of their expenditure on the three services in 1984-85. In October 1986 the Department again wrote to health boards reminding them of the April 1988 deadline for putting all their support services out to tender (NAO, 1987, para. 4.20). (The three Islands health boards continued to be exempt).

Some idea of the different path the Scottish NHS took can be gained from the National Audit Office evaluation at the end of September 1986. End September was the date when the English health authorities were expected to have fully completed their programme of tendering (NAO, 1987, para 4.8). In England, 43\% of support services by value had been awarded. The corresponding proportions for Wales and Scotland were much lower at $8 \%$ and 2\%, respectively (NAO, 1987, paras 4.8 and 5.5). The lower proportions for Wales and Scotland have several possible interpretations. One commonly mentioned is spatial: for example, there is a North/South divide in Britain. Alternatively, there is a centre/periphery contrast, with London and the South East of England representing the centre and the North of England, Scotland, Wales [and Northern Ireland] representing the periphery context. Neither explanation stands up to the evidence given below.

Information on implementation by English RHA at the end of September 1986, in respect of value of services by invitations to tender, is given in figure 1. The overall value for invitations to tender for all services and all RHAs at this date is $68 \%$, and corresponds to the estimate of $48 \%$, cited above, for value for contracts awarded. The fifteen RHAs are placed into five groups based on geographic proximity, and in turn are ordered in terms of their distance from London, with group 1 being closest to London and group 5 being farthest distant. If distance mattered, one might expect 
implementation to be highest in group 1 and lowest in group 5. This is not the case. If any systematic variation can be traced, and it is clearest for laundry services, the proportion was higher the farther the distance from London. It is important to point out that Scotland, in this respect, was not the only outlier--it is also the case for Northern Ireland. As late as July 1988, only $3.9 \%$ by value had been submitted for tendering (NI, DHSS, 1988).

\section{$\ll<<<$ Figure 1 About Here $\gg>>>$}

The virtual absence of tendering in Scotland did not last much longer. The National Audit Report, published in April 1987, was explicit in its comparison between Scotland, England and Wales. In June 1987, a Conservative government was reelected, and Michael Forsyth was appointed a Parliamentary Under-Secretary at the Scottish Office with responsibility for Scottish education and health. Forsyth was already well known as an advocate of privatisation. Margaret Thatcher was later to describe him as "[T]he real powerhouse of Thatcherism in the Scottish Office..." (Thatcher, 1993 p 620). Forsyth seems to have been given a free hand, right from the start, to ensure competitive tendering was introduced throughout the Scottish NHS. He "inaugurated" a meeting, held on 2 October, between health board chairmen and managers and representatives of the trade associations for contract cleaners and caterers, and Grant Thorton Management Consultants. The latter group of contractors and the firm of management consultants all had experience of market testing in the English NHS.

Contractors had become seriously interested in the Scottish market by this time. One reason being that most of the first round of tendering in England had been completed and few contracts were due for renewal. Contract cleaners would have been particularly interested; with one exception, contract caterers were much less so (Milne, 
1993 and 1997). In addition (as noted above), the Scottish market was larger than any English RHA and offered contractors the prospect of significant additional new business.

The October meeting was followed by an official letter from the Home and Health Department of 11 December 1987 to the health boards (SHHD, undated). The Minister was described as "very concerned", and health boards were to seek tenders for blocks of domestic and blocks of catering contracts and have them let by end April 1988: being at least two blocks of domestic and two blocks of catering services for each of the health boards. Borders, Dumfries and Galloway, Highland and each of the three Islands Health Boards were excepted, and each was given targets of at least one block of domestic and one block of catering services. In total, a minimum of 24 blocks of domestic and 24 blocks of catering contracts were to be let by end April 1988 . Laundry services were explicitly excluded from the requirement to be put out to tender unless new facilities were to be brought into operation. Determined as the 1987 guidance was, the immediate targets for April 1988 would have covered only a modest proportion of all NHS hospitals, even for domestic and catering services.

By 27 February 1988 Forsyth felt able to announce on Radio Scotland that all health boards had agreed to invite tenders for in-house services. One wonders what Forsyth had in mind, when stating: "No additional powers are required in this area", had he felt unable to make such an announcement (Hansard, 25 May 1988 written answer col. 184). As one senior servant has recently written:

"I think that there can be no doubt, in particular in the wake of the 1987 guidance, that Health Boards were clear as to what was expected of them. And for those few that questioned the force of the guidance, it was also made quite clear that if they felt that they could opt not to apply the guidance, then that guidance could very rapidly [be] turned into a direction and that their choice would thereby be removed from them." 
The effect of the 1987 Forsyth initiative was dramatic. The number of new domestic services contracts increased from 3 in 1987, to 20, 60, 23 and 13 in the next four years (Milne, 1993, table 1). The corresponding data for catering were 3, 9, 47, 17 and 10 contracts. Health boards may not have responded as quickly as the Minister had indicated in December 1987, but over the longer term they far exceeded the immediate targets set.

\section{Did Competitive Tendering Work?}

\subsection{Evaluation Methods}

In this section, the "Forsyth initiative" is evaluated in the same terms as used by the National Audit Office, with the main criteria being "coverage" and "costs saved". Comparisons are made to England in the first three years of the implementation (i.e. to the end of September 1986). A similar three-year period is used for Scotland (i.e. to the end of March 1991). The services covered by central government guidance are: (1) domestic, (2) catering and (3) laundry/linen. The premises covered are hospitals, and other NHS premises such as clinics, health centres and health board offices. In this evaluation the experience of contracting is restricted to hospitals, and more particularly to the 273 hospitals identified in the annual publication Scottish Health Service Costs as open and with some staffed beds for all five financial years 1986-87 to 1990-91.

\subsection{Coverage}

It is not possible to replicate the National Audit Office report exactly, and this should be borne in mind when considering Scottish/English comparisons. Three qualifications are worth noting. First, the estimates are for hospital contracts. This is not a serious qualification. First, the focus of the 1987 initiative was to put out to competitive tender hospital domestic and catering services. Second, hospital contracts 
have tended to be much larger, by far (Milne, 1993, table 2), and account for the overwhelming proportion of NHS expenditure on domestic and catering services. And finally, once the policy of tendering for hospital services has been accepted by a health board, it is a small step to include other premises such of offices, health centres and clinics. This extension was particularly evident for domestic services, as one might expect, and they accounted for the overwhelming proportion of contracts for nonhospital NHS premises. In the cases of catering and laundry services, competitive tending for non-hospital premises was hardly an issue since these services were rarely provided or only on a very modest basis.

Second, coverage is measured in terms of staffed beds available, not cleaning or catering costs. In the period to the financial year 1990-91 published information on hospital hotel service costs was only available for the larger hospitals. However, there is some evidence that unit cleaning costs were much the same for hospitals of different sizes. This being the case, information on staffed beds available would be an adequate substitute for costs to measure the coverage of competitive tendering for domestic services, and possibly for catering as well.

Third, the contracts are identified in terms of their start date. We do not have information on the dates invitations to tender were issued or when the contracts were awarded. Of the three qualifications this is the most serious by far. As noted above, in England coverage in terms of invitations to tender by the end of September 1986 was $68 \%$, but only $48 \%$ in terms of contracts awarded. Coverage in terms of start date would be even smaller, though it is difficult to establish by how much.

Information on the number of hospital domestic and catering contacts and the extent of their coverage by end of the financial year 1990-1 is given in table 2 . The table includes one (catering only) contract put out to tender for which no award was 
made. The discrepancy between the number of contracts indicated in the table and those cited in the text above comes from the inclusion (in the text) of contracts for non-hospital premises, particularly notable in the case of domestic services. The much larger number of hospitals compared to the number of contracts is because often contracts were not for a single hospital. One extreme example is the health board that put all but one of its hospitals out to tender in a single catering contract. Notice also that the proportion of beds covered was much greater than the proportion of hospitals, and would have been the consequence of directing competitive tendering at the larger hospitals.

\section{$<<<<$ Table 2 About Here $>>>>$}

It is important to note the pace at which coverage was achieved in Scotland. By the end of March 1991, slightly more than three years after the Forsyth initiative, coverage exceeded $80 \%$ of beds for domestic and catering services in terms of the start date of contracts. The corresponding proportions of invitations to tender for England, by the end of September 1986 (and three years after the publication of official guidance) is similar for domestic services, but very much lower for catering, being only about $50 \%$.

The situation could have hardly been more different for laundry services. Existing provision was exempt from the Forsyth initiative, and by the end of March 1991 only one board wide contract and two part board laundry contracts had started. In England $80 \%$ of laundry services had been put out to tender by end September 1986. No further reference will be made to laundry services.

\subsection{Costs Saved}


In this section we focus on some of the characteristics that may have a bearing on the costs saved. The costs saved was the main economic measure of the policy's success (or failure) at that time. The 1983 Health Departments' circulars were written in terms of testing the "cost-effectiveness" of domestic, catering and laundry services. Nevertheless, health boards and authorities were expected to award contracts to the lowest tender, bearing in mind that those invited to tender had previously been vetted for their financial viability and technical competence. Further, the policy of competitive tendering was seen as one arm of the 'efficiency savings' programme current at that time, aimed at providing additional patient care without drawing on the Exchequer. Finally, previous experience of significant cost saving achieved from competitive tendering in the Ministry of Defence would not have gone unnoticed (Hall, 1984). Estimates are therefore made of the costs saved for the same set of 273 hospitals over the financial years from 1986-87 to 1990-91 inclusive.

The contract characteristics considered are: type of service, that is single service or mixed services; value of the contract put out to tender; and who won the contract. Of the 84 contracts with domestic services, 59 were domestic only contracts and 25 included one or more other services as well. Of the 76 contracts with catering services, 55 were catering only and 21 included one or more other services. A distinctive feature of the 21 mixed catering contracts is that they all included domestics services. This considerable overlap between the mixed domestic and mixed catering contracts is the result of the distinctively Scottish practice at that time of putting hotel service contracts out to tender. We therefore exclude the mixed service contracts when differentiating domestic from catering contracts, and largely limit comparisons to the 59 domestic only and the 55 catering only contracts. 
Information is given in table 3 on values of contract in terms of pre-tender cost. Separate distributions are given for the single service domestic and catering contracts and the mixed domestic contracts. All indicate a wide variation in value.

$$
\ll<<<\text { Table } 3 \text { About Here } \gg>>>
$$

Originally hospital domestic and catering services were provided in Scotland by direct service organisations [DSOs]. Usually the DSOs retained the contracts. Those lost to contractors were a distinctive group, mostly for single service domestic contracts. DSOs won 69 of the 84 domestic contracts, the 15 contracts won by contractors were only for single services. Contractors won none of the 25 mixed domestic contracts. Contractors won three catering contracts, all in the largest group by value. Catering contractors, of course, won none of the mixed catering contracts. Contractors' experience in Scotland thus matched the English experience which had preceded it, both in terms of service and contract size. The complete failure of contractors to win hotel service contracts should however be noted.

Cost saving is defined as the difference between the tender price and the previous cost, both expressed in annual terms and in current prices. This is the method used by the National Audit Office. Information is given in table 4 on the costs saved, so defined, for single domestic, single catering and mixed domestic contracts. All three groups indicate a large variation. For all but three contracts, tendering resulted in a drop in expenditure measured in current prices. The drop in real terms - that is, adjusted for changes in the price level - would have been larger still.

$$
\ll<<\text { Table } 4 \text { About Here } \gg>>>
$$

Two approaches are used in this paper to estimate the magnitude of cost savings. The first uses the approach we believe was followed by the National Audit Office. This method gives each $£ 1$ of saving equal weight. Using this method, the 
saving for all relevant contracts is aggregated and then compared with the aggregate of the corresponding pre-contract values. On this basis, the cost saving in Scotland for single domestic, single catering and mixed domestic services were $23 \%, 15 \%$ and $14 \%$.

The preceding English experience concentrated on single service contracts, and the corresponding proportions for domestic and catering services were $26 \%$ and $10 \%$, respectively (NAO, 1987, table 4). Bearing in mind that health boards already had efficiency savings equivalent to $10 \%$ of hotel costs imposed in the financial year 198586, and that the coverage of catering was much more extensive in Scotland, the savings achieved were greater in Scotland.

The second approach recognises the large variation in costs saved, and that this variation may be due to systematic as well as to random effects. To test this possibility we give each contract equal weight, with small contracts having the same weight as large ones. The domestic and catering service contracts are then divided into sixteen possible sub-sets, two sub-sets each for winner, contract size, service and service type. Pairs of these sub-sets are then compared to test whether differences in costs saved were unlikely to have come by chance. Data for the various sub-sets are given in the Appendix 1. Here we simply report the results where observed differences in costs saved are highly unlikely to have occurred by chance. The influences tested are, in the following order: winner (DSO or contractor); contract size ('small' or 'large'); service (domestic or catering); and service type (single or mixed).

There is an a priori expectation that cost savings would be larger if contractors win the contract. DSOs were the incumbent in all cases. Contractors not merely had to match the DSO bid but, in the period under study, had to shade it sufficiently to offset the "below the line" redundancy and other severance costs from the DSO losing the contract. On average, the costs were $12 \%$ of the annual price of the contract in the 
evaluations for domestic only contacts. The corresponding proportion for mixed domestic contracts was lower at $6 \%$.

In two of the three pairs of comparisons contractors did indeed reduce costs more than did DSOs, with corresponding mean values around $29 \%$ and $13 \%$, respectively. In England contractors were also found to have made greater reductions than DSOs for domestic and catering contracts, particularly in the initial period when compulsory competitive tendering was implemented (NAO, 1987, paras. 2.29 and 2.32).

The impact of contract size was tested by dividing the contracts into two groups: 'small' for contracts whose previous cost was less than $£ 0.6 \mathrm{~m}$ in current prices; and 'large' for contracts whose value was greater. We have no $a$ priori view as to which group would experience larger cost savings. Five pairs of comparisons are possible, but in no case are the cost reductions significantly different between 'small' and 'large' contracts.

We have already indicated that English experience suggests the cost savings would be greater for domestic than catering services. Five pairs of comparisons are possible using the Scottish data, but only one confirmed this experience using the second approach. The exception is large single service contracts retained by DSOs, whose mean values were $22.3 \%$ and $13.5 \%$ for domestic and catering services, respectively.

The final characteristic is service type, single versus mixed service contracts. The limited evidence above suggests the cost savings for catering was less than for domestic services. If the difference were sufficiently large this would impact on the single versus mixed differential. It does so for one of the four possible comparisons, being large domestic contracts retained by DSOs. The savings are greater, as expected, 
for the single as against mixed service contracts, with mean values of $22.3 \%$ and $12.0 \%$, respectively.

\section{Discussion}

This paper has largely been concerned with establishing whether competitive tendering was effectively compulsory in the Scottish NHS. The NHS stands apart from parallel policies in central and local government. In central government, ministers could exercise direct control. In local government statutory measures were introduced with central government monitoring to ensure compliance. The Conservative Government chose a more light handed approach in the case of the NHS, and left responsibility for implementation to the various health boards. The result was the policy was all but ignored at first in Scotland, Wales and Northern Ireland.

The situation in Scotland changed dramatically in 1987. A transformation was achieved within a few months and the English experience, at least for two of the three services, was subsequently more than matched. Much of the credit must surely go to Michael Forsyth. Prime Minister Margaret Thatcher recognised a kindred spirit, and took a close interest in him. His subsequent career might be described as the 'rise and rise of Michael Forsyth MP'. Within a short period - by September 1990 - Forsyth was promoted to become a Minister of State at the Scottish Office. After a period in office down South, he was further promoted, by John Major, in July 1995 to become Secretary of State at the Scottish Office. There he remained until the Conservative Government lost the 1997 general election.

Even talented politicians, nevertheless, need opportunity, and this was available at the right time for Forsyth. Market testing requires contractors, and contractors prefer 'willing partners'. The description 'willing partner' hardly applied to the 
Scottish health boards, and so contractors concentrated on the English market. However, by 1987 new markets had to be found if their business were to expand. Scotland promised to make a significant addition. Contract cleaners were willing to do business. Unusually, for that time, so also was a major contract caterer, already based in Scotland. Its established business had been to serve North Sea oil and gas exploration companies. However, its established business was in decline and NHS catering offered the opportunity to make good. All three catering contracts that were won by contractors were won by this one.

\section{Postscript}

So far we have written about the period up to 1991 , and the ability of a national government to export unpopular policies to devolved administrations. There have been important developments since then, but the principle of putting NHS nonclinical support services out to competitive tender, now described as 'market testing', has not been abandoned. In chronological terms, the following significant events merit a mention.

First, was the publication in November 1991 of the White Paper Competing for Quality (H M Treasury, 1991). Not only was the principle of market testing extended to other support services, but quite significantly there was a shift in the emphasis of its purpose. As the title of the White Paper suggests, and as its text details:

"Competition does not mean invariably choosing the cheapest service: it means finding the best combination of quality and price which reflects the priority of the service." (Ibid, p 1)

Second, was the creation of NHS trusts to facilitate the introduction of the internal market. The first Scottish trusts were formed in April 1992 and the last in 
April 1995. By then the process was virtually complete, and only the three Islands Health Boards have directly managed units. The trusts took over the health boards' responsibility for implementing the policy of market testing hospital support services. In terms of the use of management resources the policy must have had a low priority during this period of re-organisation.

Third, was the realisation around 1993 that the European Community's Acquired Rights directive might apply to the market testing of publicly funded services. The directive is designed to protect workers' pay and conditions of service on their transfer from one employer to another. Two consequences of significance are identified. First, the rationale of 'below the line' severance costs in the evaluation of tenders, should DSOs lose to contractors, has disappeared. It is now be easier for contractors to win, and they would be more willing to tender. DSOs, wishing to retain contracts, now have to be more cost effective. Second, and at least temporarily, the directive created great uncertainty. The following quote from the Scottish Office guidance issued in October 1993 gives an indication of its flavour: surely sufficiently strong to deter all but the most determined participants from tendering.

"... it should be clearly understood that the guidance therein gives the current position of TUPE [the UK legislation relating to the directive] and is subject to amendment depending on the Court decisions both in the UK and the European Court of Justice. The NHS Management Executive in Scotland will not be responsible for any damages claimed by contractors or Health Boards following decisions taken as a result of this guidance." (Scottish Office, 1993, Annex G para 1, emphasis in the original).

The final significant event was the Scottish Office guidance issued in April 1998 (Scottish Office, 1998). Two points are worth identifying. First, staff pay and conditions of service now have some protection when seeking value for money in the management of support services. And second, market testing was the method of 
securing improvements in quality and value only after other routes, usually comprising partnerships of some form, had been tried.

In conclusion, the ground rules for competitive tendering of NHS non-clinical support services have changed since the policy was introduced in 1983 in Scotland by a Conservative government. However, the principle of competitive tendering, to secure quality and value for money, remains under New Labour. 


\section{References}

H M Treasury (1993) Competing for Quality Cm 1730, HMSO: London.

Hall, J (1984) "MOD saves 40 per cent on cleaning costs", Contract Services, April/May, pp 6-7.

Information and Statistics Division, National Health Service in Scotland Scottish Health Service Costs, annual, ISD: Edinburgh.

Levitt, R, A Wall and J Appleby (1995) The Reorganised National Health Service, $5^{\text {th }}$ edition, Chapman \& Hall: London.

Milne, R G (1993) "Competitive tendering of NHS hotel services in Scotland, 19831991” Scottish Affairs, No 3, Spring, pp 135-146.

National Audit Office (1987) Competitive Tendering for Support Services in the National Health Service, HC 318, HMSO: London.

Northern Ireland, Department of Health and Social Security (1988) "Competitive tendering in the provision of domestic, catering and laundry services", Circular HSS(CI)1/88, DHSS: Belfast.

Scottish Home and Health Department (1979) Structure and Management of the NHS in Scotland, HMSO: Edinburgh.

Scottish Home and Health Department (1983) "Use of commercial contractors by the NHS”, NHS Circular 1983 (GEN) 13.

Scottish Home and Health Department (1984) "Use of contractors by the NHS", NHS Circular 1984 (GEN) 14.

Scottish Home and Health Department (undated), no title, signed by Hugh Morison, deposited in the House of Commons Library. 
Scottish Office, Department of Health for Scotland (1998) "Management of support services in the NHS in Scotland: Quality and value", Circular MEL(1998)32, dated 29 April.

Scottish Office, NHS Management Executive in Scotland (1993) Market Testing in the NHS: Guidance for Health Boards and NHS Trusts, NHS Management Executive in Scotland: Edinburgh.

Social Services Committee (1986) Public Expenditure on the Social Services, Session 1985-86, Fourth Report, Volume 11, Minutes of Evidence and Appendices, HC 387-II, London: HMSO.

Thatcher, M (1993) The Downing Street Years, London: HarperCollins.

Walsh, K (1995) Public Services and Market Mechanisms: Competition, Contracting and the New Public Management, London: Macmillan.

Woodward, M and L M A Francis (1988) Statistics for Health Management and Research, London: Arnold. 


\section{Table 1}

Expenditure on hotel services, by service and health board, financial year 1984-85 ( $£ 1,000$ s)

$\begin{array}{lrrrr}\text { Health board } & \text { Cleaning } & \text { Catering } & \text { Laundry } & \text { All services } \\ \text { Argyll and Clyde } & 3,937 & 4,423 & 1,319 & 9,679 \\ \text { Ayrshire and Arran } & 2,708 & 3,740 & 868 & 7,316 \\ \text { Borders } & 808 & 1,016 & 250 & 2,074 \\ \text { Dumfries and Galloway } & 1,403 & 1,905 & 382 & 3,690 \\ \text { Fife } & 2,631 & 3,270 & 876 & 6,777 \\ \text { Forth Valley } & 2,491 & 3,547 & 869 & 6,907 \\ \text { Grampian } & 5,128 & 5,708 & 1,305 & 12,141 \\ \text { Greater Glasgow } & 12,344 & 16,043 & 4,112 & 32,499 \\ \text { Highland } & 1,886 & 1,877 & 520 & 4,283 \\ \text { Lanarkshire } & 4,456 & 5,333 & 1,276 & 11,065 \\ \text { Lothian } & 7,974 & 9,382 & 2,172 & 19,528 \\ \text { Orkney } & 191 & 177 & 79 & 447 \\ \text { Shetland } & 172 & 216 & 90 & 478 \\ \text { Tayside } & 5,262 & 6,534 & 1,743 & 13,539 \\ \text { Western Isles } & 240 & 394 & 150 & 784 \\ \text { All health boards } & 51,631 & 63,565 & 16,011 & 131,207\end{array}$

Source: Hansard 25 November 1985, written answer, col. 424. 
Table 2

Hospital coverage, end March 1991, select features

Feature

Number of contracts

Number of hospitals

Proportion of hospitals (\%)

Average number of staffed beds

Proportion of staffed beds (\%)
Domestic

84

187

68

44,285

85
Catering 76 184 67

42,725

82 


\section{Table 3}

Distribution of contracts by size and service

$\begin{array}{lccc}\text { Size }(£ \mathrm{~m}) & \text { Domestic only } & \text { Catering only } & \text { Domestic mixed } \\ \text { Less than } 0.5 & 16 & 12 & 9 \\ 0.5 \text {, less than } 1.0 & 27 & 19 & 5 \\ \text { 1.0, less than } 1.5 & 7 & 10 & 6 \\ \text { 1.5 and over } & 3 & 5 & 5 \\ \text { Missing values } & 6 & 9 & 0 \\ \text { All sizes } & 59 & 55 & 25\end{array}$




\section{Table 4}

Distribution on costs saved, by service (\%)

$\begin{array}{lccc}\text { Costs saved (\%) } & \text { Domestic only } & \text { Catering only } & \text { Domestic mixed } \\ \text { Less than } 0.0 & 2 & 1 & 0 \\ \text { 0.0, less than } 10 & 11 & 16 & 8 \\ \text { 10, less than } 20 & 14 & 16 & 14 \\ \text { 20, less than } 30 & 10 & 10 & 2 \\ 30 \text { and over } & 16 & 3 & 1 \\ \text { Missing values } & 6 & 9^{*} & 0 \\ \text { All values } & 59 & 55^{*} & 25\end{array}$

Note: * No award was made in the case of one contract

Source: Scottish Office Department of Health 


\section{Figure 1 Extent of coverage, England by RHA group and service, end September 1998}

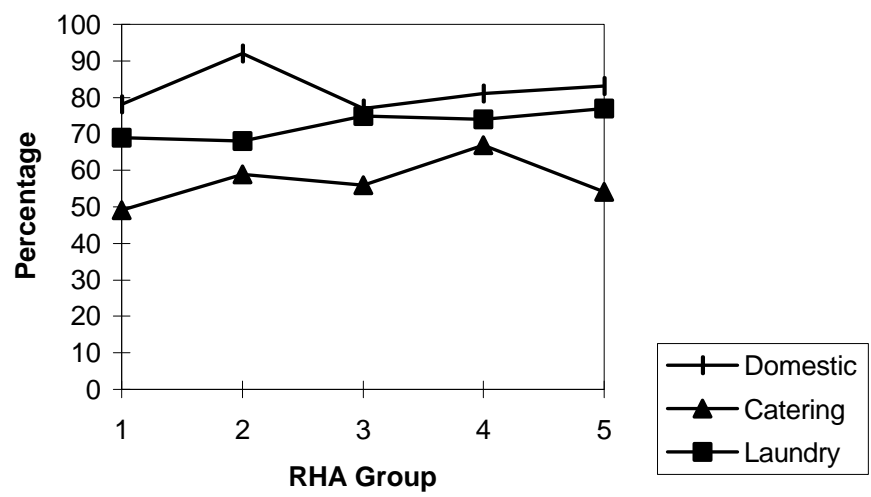

Notes:

RHA Groups:

1. The four Thames RHAs

2. East Anglia, Oxford and Wessex RHAs

3. South Western, Trent and West Midlands RHAs

4. Merseyside, North Western and Yorkshire RHAs

5. Northern RHA

6. The Regional Health Authority values are calculated on the basis of giving each constituent district health authority equal weight, irrespective of size of district. The district health authority data were obtained from Hansard, 25 November 1986, written answer, cols 21320. The group data are the average of the individual Regional Health Authority values.

Source: Hansard, 25 November 1986, written answer, cols. 213-20. 


\section{Appendix 1}

\section{Analysis of Costs Saved}

Pairs of mean values of the various characteristics, given in the table A1 below, are compared on a pairwise basis. For example, the characteristic 'winner' is tested by comparing the three pairs where the only difference is 'winner', being in this case: small/domestic/single, large/domestic/single and large/catering/single. The comparisons follow standard procedures, a description of which may be found in Woodward and Francis (1988), section 7.9.

The characteristics are assumed to have their own population variances, and the different hypotheses are tested on the basis of a 95\% confidence interval. For example, the characteristic 'winner' may be tested for small/domestic/single contracts, whose mean values are $13.5 \%$ for DSOs and $30.4 \%$ for contractors. The difference in means is therefore $16.9 \%$. The standard deviation is $7.1 \%$. The degrees of freedom for the two small samples is 10.9 , giving a Student's t-ratio of 2.201 for a two-tail test, and 1.796 for a one-tail test at the $95 \%$ confidence interval. In the case of 'winner' we hypothesise cost savings will be greater for contractors, so a one-tail test could be used. The $95 \%$ confidence interval is $16.9 \%+/$ $7.1 \% * 1.796$, which lies between $4.1 \%$ and $30.0 \%$. This range does not contain zero, and so contractors did indeed reduce costs more for this sub-set. In fact the more stringent two-tail test would also have shown contractors reduced costs more. 
Table A1

Summary descriptive statistics of costs saved by contract sub-set

$\begin{array}{lccc}\text { Contract sub-set } & \text { Mean } & \text { Sample size } & \begin{array}{c}\text { Standard } \\ \text { deviation } \\ \text { Winner/size/service/service type }\end{array} \\ & (\%) & & (\%) \\ \text { 01 DSO/small/domestic/single } & 13.5 & 20 & 18.6 \\ \text { 02 DSO/large/domestic/single } & 22.3 & 19 & 11.9 \\ \text { 03 DSO/small/catering/single } & 14.5 & 19 & 12.8 \\ \text { 04 DSO/large/catering/single } & 12.0 & 24 & 8.2 \\ \text { 05 DSO/small/domestic/mixed } & 13.9 & 13 & 10.5 \\ \text { 06 DSO/large/domestic/mixed } & 13.5 & 12 & 5.8 \\ \text { 07 DSO/small/catering/mixed } & 14.6 & 11 & 11.3 \\ \text { 08 DSO/large/catering/mixed } & 12.3 & 10 & 5.0 \\ \text { 09 Contractor/small/domestic/single } & 30.4 & 6 & 14.0 \\ \text { 10 Contractor/large/domestic/single } & 27.5 & 8 & 14.3 \\ \text { 11 Contractor/large/catering/single } & 27.4 & 3 & 8.4\end{array}$

Notes

- Table based on samples of 84 domestic contracts whose pre-tender value is known in 78 cases, and 76 catering contracts whose pre-tender value is known in 67 cases. 'Small' contracts have a pre-tender value of $£ 0.6 \mathrm{~m}$ in current prices, 'large' contracts have a higher value.

- Contracts are found in all eight sub-sets for those won by DSOs, but only for three of the sub-sets for those won by contractors. Contractors won none of the mixed service contracts. 
The results of the pairwise comparison are given in table A2 below. Given eleven different sub-sets, there are 55 possible comparisons, but only 17 are of interest: they are identified in the table. Three test for the importance of winner, five each for size and service, and four for service type. The variation in costs saved is so great, given the sample size in each sub-set, that in only four cases are the differences unlikely to have come about by chance. They are indicated by upper case letters.

Table A2

\section{Analysis of difference of means}

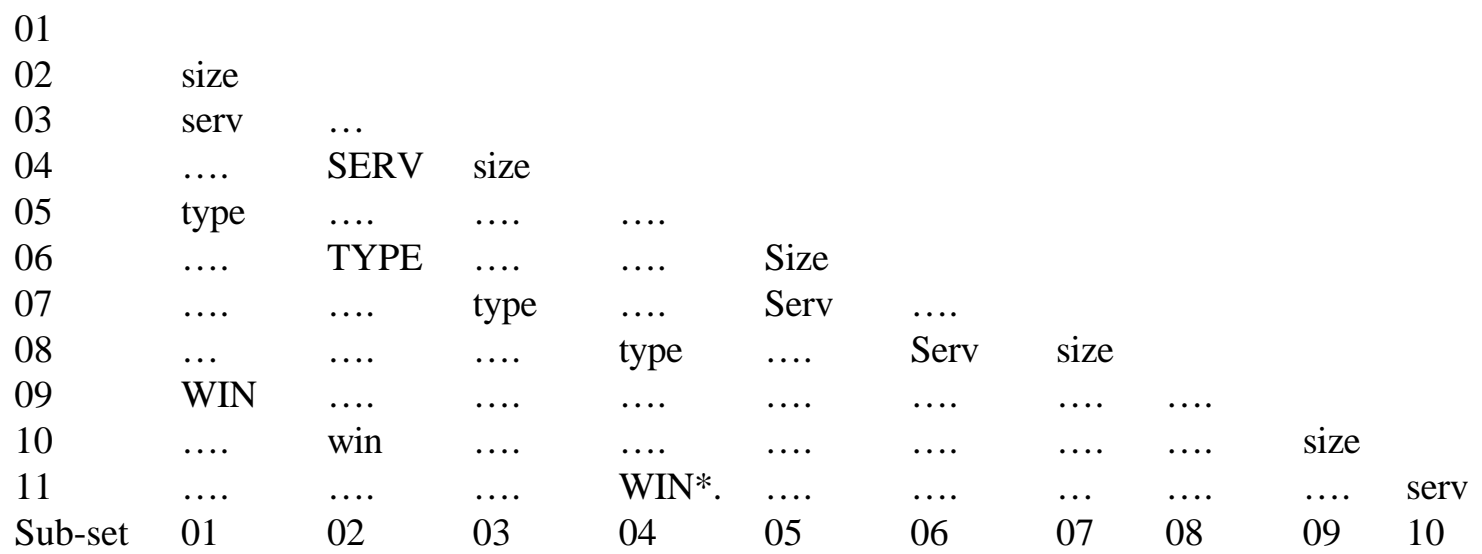

Notation:

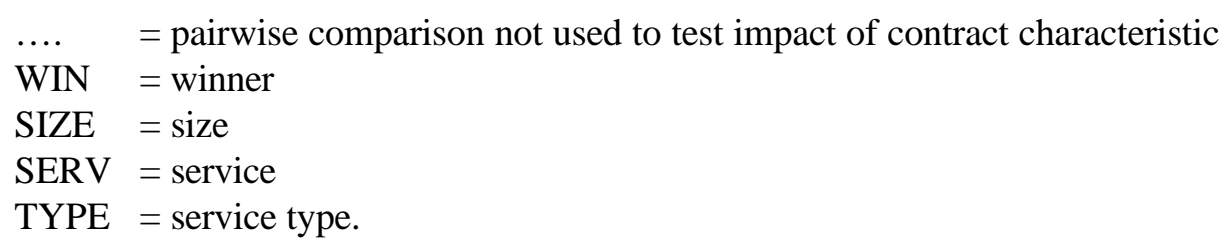

Upper cases denote means different at the $95 \%$ confidence interval using the two-tail test.

Suffix $*$ denotes means different using a one-tail test 